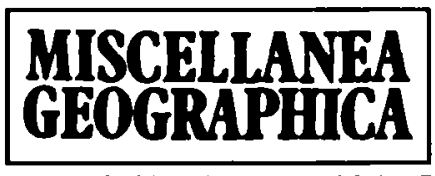

WARSZAWA 1992 Vol. 5

Mieczysław Adamowicz, Selahettin Eraktan, Janusz Gudowski, Wladysław Piskorz

\title{
ADJUSTMENT OF AGRICULTURE TO THE REQUIREMENTS OF MARKET ECONOMY. OBSERVATIONS FROM TURKEY AND POLAND IN 1991
}

What happens to the rural sector in countries that implemented stabilization programme is a very debatable question. Does it go better or not; how it is in the short-, medium- and long-run; is agriculture to be partly excluded from stabilization measures - all these points ought to be the subject of research due to the importance of food economy.

Turkish and Polish agriculture pass a similar stage of transition. Some general economic features are common to both countries, e.g. in 1989 GNP per capita which was 1370 and 1790 USD respectively (but last years' significant growth in Turkey and decline in Poland) as well as predominant mixed peasant farming.

Economic stabilization precautions were undertaken in Turkey in January 1980. One of their main objectives was to introduce a new economic model which depends on private enterprise and to create a more functional national economy by way of the prices that freely realise in the market. The precautions necessary for the new programme also caused the reorganizing of the agricultural policy. In the early and mid-80's the prices of inputs essential for agriculture were liberalized to a large extent. Subsidies applied to rural credits have been reduced and the number of agricultural products have been excluded from support (most of cash crops and livestock).

But it has been known that liberal economy and agricultural sector are not harmonized with each other and even in the most liberal countries the state effectively intervenes in agriculture. The deviations from liberal economy principles in agricultural sector have also been seen in Turkey, e.g. credit interest at 35$42 \%$ level, that is much below inflation rate; decreased value added tax; no land tax etc.

After a decade of liberal policy important changes in Turkish agriculture may be observed. More and more farmers choose the way of production for market instead of self-consumption. It caused the increase of types of products and improvements of quality. Development of agroindustry is accompanied by general adjustment processes in rural sector. 
Stabilization programme launched in Poland on January the 1st, 1990 resembles the Turkish programme to a large extent. Classical instruments of this action, such as price liberalization, reduction of subsidies and anti-inflationary measures have been used. As a result of the overall change in Poland farmers are facing completely new phenomenons that during past 40 years were never observed here, such as:

- the shrinking of internal market for selling agricultural products;

- increased competition of semi-controlled food import of subsidised food from Western Europe;

- increased risk and uncertainty in farming;

- aggravation of distorted relationship between prices received and paid by farmers, and between different agricultural products;

- limitation of the internal and external sources of accumulation for investment and working capital.

Pilot studies organized in 1991 in Poland and Turkey by few scientific institutions $^{1}$ aimed at monitoring response of the particular peasant households to the stabilization processes. Methodological description of field research procedure is included in the paper "Feasibility...". Data received from the samples served to investigate cross section function of agricultural income (in Turkish case global product). Independent variables were: human factor (age of the head; farm labour potential); productive environment (farm size; area of drainage/irrigation) and income ranks of the main products (i.e. income shares of cereals, industrial plants, other cash crops; milk; beef; pork; others). In case of the Polish sample, that was much more detailed than the Turkish one, the main problem of the calculation was to consider properly the real cost of production. None enquiries could supply the authors with the reliable data on costs borne by peasant farms. As a result, the authors used average costs coefficients calculated in 1991 by the Institute of Agricultural Economics in Warsaw for 1600 peasants' farms that accepted book accounting for the research purposes. The average cost covers all real costs with the three highest ones: purchased fertilizers, hired services and depreciation on premises.

Paradoxically, while using these data for model estimation it turned out that at the actual farmgate prices the bulk of plant production (excluding the most profitable vegetable seeds plantations) as well as milk, beef and pork production is unprofitable (sic!). Farmers covered by the sample survey represent mostly good and moderately good farms. According to the authors' estimates, the actual real costs are at the most at $60-70 \%$ of the above-mentioned normative costs, that after the reduction have been consequently used for the model evaluations.

\footnotetext{
${ }^{1}$ Institute of Developing Countries (University of Warsaw), Institute of Agriculture Economics (University of Ankara) in collaboration with the Institute of World Agriculture (Warsaw Agricultural University) and Cracov Institute of Tropical and Subtropical Agriculture and Forestry.
} 
Due to the small size of the samples, the evaluation may show only some general tendencies observed in both countries. It reveals:

(1) that enlarging farm area is in both cases the primary factor to improve farm income;

(2) importance of labour input. The balance of labour estimated for some enquired Turkish farms shows a tremendously labor-extensive way of production with 20-30 days of the work annually on the farm of 5-6 ha. In the Polish case the farms engaging more of their own and hired labour generally do better than the other ones;

(3) decreasing significance of milk, cereals and some industrial plants in Polish case (this year in some regions peasants even ploughed out the rapeseed instead of harvesting it). The situation of farms with a more extensive type of production (cereals-livestock) is at present very difficult;

(4) also in the Polish case slower adaptation of younger farmers to the new situation. This phenomenon may be explained perhaps in psychological terms. Older generation (age of enquired farmers varied from 27 to 80 years) survived the actions against peasantry under former regime. Younger farmers as well as their wives represent another type, not so stubborn. As one of recently retired farmers in Brudzeh Maly village said: "...young people prefer 'clean' cereal cultivation. They avoid pig breeding as too difficult and not enough renumerative, but at present it is one of the solutions to survive under so heavy credit interest and so costly services...".

What solutions are preferable and what adjustment processes may be seen in both countries? In Poland farmers have faced stabilization programme only since January 1990 but even in such a short period one may observe the efforts to avoid the consequences born by stabilization measures. It is characteristic that the operators of larger and better equipped farms would be willing to enlarge their farms area in order to decrease actual costs per production unit and to make profit of economy of scale. Unfortunately, the lack of policy towards improvement of agrarian structure is a vulnerability in Poland. On the other hand, marginal and small farmers have no other job opportunities, especially now. In Turkey this situation changed and at present poorer sections of rural population seem to have better alternatives of agriculturally related employment.

In the Polish case those small farmers that have no opportunities to implement very specialized type of production enter natural economy that may be commented as the first stage of structural change of rural sector. Others try to find the ways to defend their incomes. The farms specialized in intensive cereal cultivation that have difficulties to market the output want to focus on their own fodder concentrates and bruised grains and to intensify young cattle breeding. Some others produce vegetable seeds, the most profitable product, that is however very risky and limited in terms of area and cannot be treated as the general solution. The highest income was notified by household No. 13 at Uniejewo village of 23 ha with 10 ha under cereals (up to 7.5 tons of wheat per ha). All the cereals were fed off as fodder concentrate and bruised grain by livestock, hogs 
and 11 milk, cows. The average milk yield was 4,5001 yearly, which is a good result on the country scale.

Weaker farms try to develop pig breeding in spite of dislike of younger farmers. Between July and September 1991, when the field research in Poland was carried on, more than $100 \%$-increase of market price was observed in case of piglets, which indicates growing interest in pig breeding. Also some weeker farms suspended milk selling to use it as the fodder.

The Turkish case shows that agriculture seems to overcome the most difficult phase of stabilization. Farmers take credits at the same interest as in Poland, which discourages Polish peasants. The demand for labour intensive-products, such as grape, is high and local manufacturing (wines, vinegard, juice, raisins) helps to reduce labour pressure. It is worth emphasizing that in recent years there has been a visible interest in investing money in some activities in rural areas by Turkish gesterbeiters employed in Western Europe (mills, milk manufacturing). Furthermore, the political intention of the authorities is to support cereal cultivation. It also proves that in the case of rural sector the preliminary stage of stabilization is successfully over. 